EMBRYARIDDLE
Aeronautical University

SCHOLARLY COMMONS

\section{International Journal of Aviation,} Aeronautics, and Aerospace

$6-12-2018$

\title{
Competitiveness of Hybrid Electric Aircraft on Short Range Scheduled Flights
}

Johannes Anton

Embry-Riddle Aeronautical University, http.jo@googlemail.com

Hans-Joachim K. Ruff-Stahl

Embry-Riddle Aeronautical University, ruffha@erau.edu

Follow this and additional works at: https://commons.erau.edu/ijaaa

Part of the Aerospace Engineering Commons, and the Business Administration, Management, and Operations Commons

\section{Scholarly Commons Citation}

Anton, J., \& Ruff-Stahl, H. K. (2018). Competitiveness of Hybrid Electric Aircraft on Short Range Scheduled Flights. International Journal of Aviation, Aeronautics, and Aerospace, 5(3). https://doi.org/10.15394/ ijaaa.2018.1240

This Article is brought to you for free and open access by the Journals at Scholarly Commons. It has been accepted for inclusion in International Journal of Aviation, Aeronautics, and Aerospace by an authorized administrator of Scholarly Commons. For more information, please contact commons@erau.edu. 
Hybrid electric aircraft have received much attention in recent years due to their potential to reduce the environmental impact of civil aviation, which contributes two percent of the global $\mathrm{CO}_{2}$ emissions from transport (Sustainable Aviation, 2008). In Europe, the European Commission aims to reduce aviationrelated $\mathrm{CO}_{2}$ emissions compared to the year 2000 by $75 \%$ until 2050 (European Union, 2011). To achieve lower $\mathrm{CO}_{2}$ emissions, the transition to hybrid electric aircraft is viewed as a significant step. In addition to increased fuel efficiency, these aircraft would emit less noise and fewer particles. Another indicator that hybrid electric aircraft engines might be the next step in propulsion evolution is the fact that gas turbines as the state-of-the-art propulsion technology have reached saturation in fuel efficiency (Stricker, 2003). Every further development would mean only small improvements in efficiency while significantly adding more complexity.

To this date, however, little research has been done on the economic benefits of the hybridization of civil passenger aircraft. Hence, the purpose of this paper is to investigate whether hybrid electric passenger aircraft with 50 seats can be competitive against the established 100 seat aircraft on short-range scheduled flights. Specifically, a hypothetically hybridized 50 seat aircraft with increased fuel efficiency is compared to a 100 -seat aircraft by cost per available seat mile (CASM). To make this case, $t$-tests are utilized to evaluate cost and efficiency. It has been found that hybridization shows promising competitive advantages compared to existing and conventional benchmarks.

\section{Literature Review}

\section{Enabling Technologies for Hybrid Electric Aircraft}

One of the critical enablers for hybrid aircraft is the advancement of lithium-ion batteries, providing higher energy density, power density, and increased levels of safety. Further, hybrid electric aircraft concepts make use of the increased degrees of freedom in the design space between aerodynamics, aeroelastics, structures, propulsion, and energy conversion, aiming to optimize the integration of the propulsive units and the energy management system for efficiency (Geiß \& Voit-Nitschmann, 2017).

Besides "soft" efficiency considerations, "hard" and rule-based safety considerations must be considered. Specifically, the engines of a modern conventional turbofan-jet aircraft shall be sized to provide go-around power in the case of the failure of the most critical engine (Pornet \& Isikveren, 2015). This scenario includes asymmetric thrust conditions and countermeasures, including opposite rudder, which not only increases drag but also increases the required 
thrust. Consequently, in the case of a twin-engine aircraft, a single-engine goaround and climb is the critical phase, which the engines must be sized for. In this case, a hybrid system can size one single gas-turbine for cruise climb power and take the additionally required power for takeoff from the batteries, while the critical case of a one-engine-inoperative-go-around can be significantly alleviated by the use of multiple electric propulsive units. During cruise, the gas-turbine runs close to best efficiency (see Figure 1) and can even be further optimized to operate at that specific design point, drastically reducing the thrust-specific fuel consumption - in other words, fuel would be saved in these phases of flight (Liu, Valencia, \& Teng, 2016 and Geiß \& Voit-Nitschmann, 2017).

Consequently, the size of a gas turbine in a hybrid aircraft can be reduced to only provide sufficient power for cruise-climb and one single, large gas-turbine would be enough. Additional power for peak demand scenarios, such as a singleengine-go-around, can be provided by the batteries. Since the gas-turbine would run at constant cruise power without the necessity for wide power variations, it could be optimized for that design point, which would enable significant improvements in fuel consumption (Liu, Valencia, \& Teng, 2016 and Geiß \& Voit-Nitschmann, 2017).

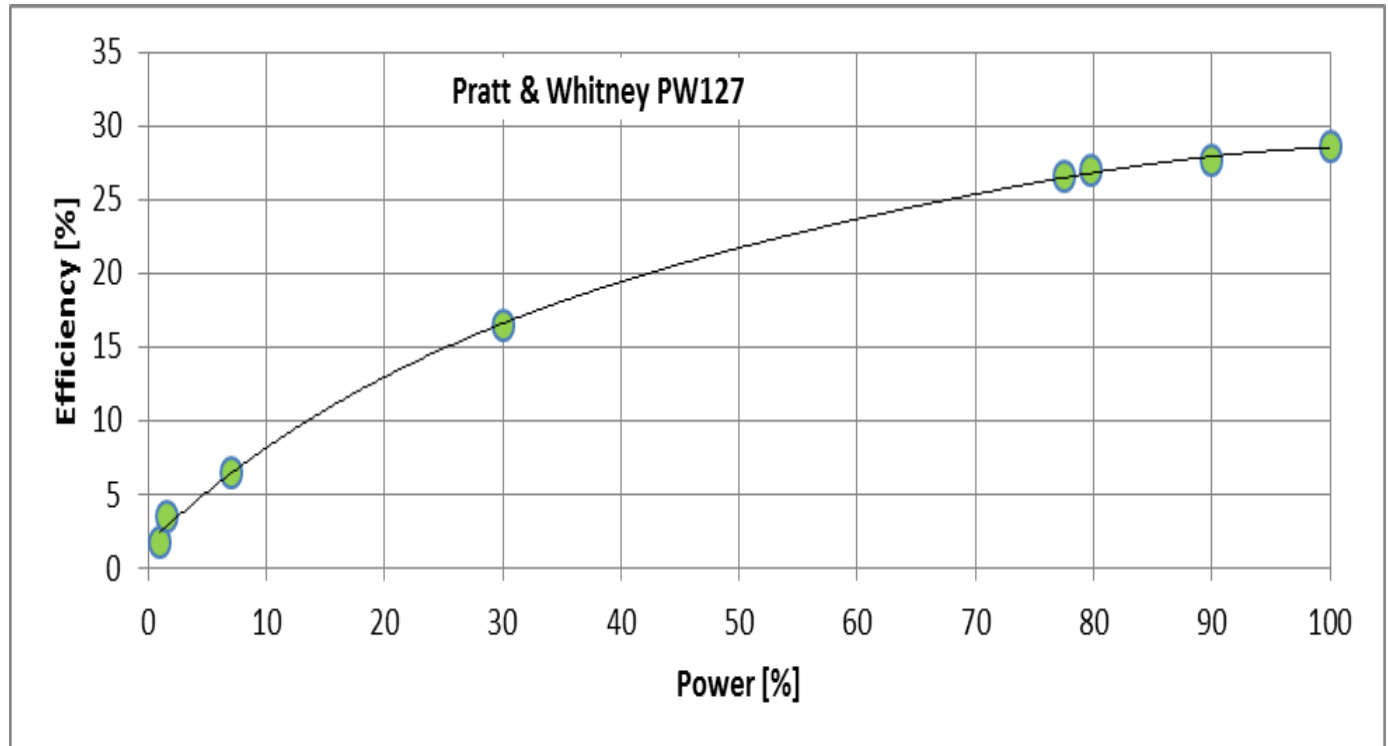

Figure 1. Efficiency versus power setting of the PW127 turboprop engine. Best efficiency is reached at full power for turboprop and turbojet engines. Data from the University of Stuttgart, as described in "Sizing of fuel-based energy systems for electric aircraft," by I. Geiß and R. Voit-Nitschmann, 2017, Proceedings of the Institution of Mechanical Engineers. 


\section{Batteries}

Thus, in hybrid applications, batteries would enable short periods of high power demand, such as takeoffs and go-arounds. Additional applications could include electric taxi exclusively from battery power to ensure zero emissions on the ground and increase efficiency: Turboprop engines and turbofans have relatively high fuel flow rates during taxi operations and reach a low point in specific fuel consumption (Geiß \& Voit-Nitschmann, 2017). Especially in the case of busy airports, the amount of taxi fuel used due to long waiting periods at the departure holding point with idling engines is of concern to the operators.

Nevertheless, batteries are ideal for quick power demand scenarios, since there is no lag such as the spool-up time in turboshaft engines, even when considering the relatively high weight of batteries about the amount and duration of thrust that can be generated. Moreover, the weight problem is expected to improve. In a recent technical report, NASA researchers investigated developments in lithium-ion batteries. As of 2015, they identified the current density levels at 80 to $200 \mathrm{Wh} / \mathrm{kg}$ for lithium-ion batteries, 250 to $300 \mathrm{Wh} / \mathrm{kg}$ for lithium-sulfur batteries and 300 to $350 \mathrm{Wh} / \mathrm{kg}$ for lithium-air/oxygen chemistries on the cell level (Dever et al., 2015). While lithium-ion batteries are already market available, the other two cell chemistries are still in development. For lithium-ion chemistry batteries, Deveter et al. (2015) expect improvements so "that the cell-level performance will continue to improve from today's average of $150 \mathrm{Wh} / \mathrm{kg}$, to approximately $400 \mathrm{Wh} / \mathrm{kg}$ within 15 years and to $450 \mathrm{Wh} / \mathrm{kg}$ within 30 years" (p 31), while lithium-sulfur batteries "will enable a commercial product with a cell-level specific energy of approximately $500 \mathrm{Wh} / \mathrm{kg}$ within 15 years and $800 \mathrm{Wh} / \mathrm{kg}$ within 30 years" (p. 32). For lithium-air batteries, he predicts "approximately $600 \mathrm{Wh} / \mathrm{kg}$ within 15 years and $1200 \mathrm{Wh} / \mathrm{kg}$ within 30 years" (p. 32).

Since the weight of aircraft subcomponents contributes in a non-linear way to the overall performance of an aircraft, these expected energy density improvements will be more significant than just the weight savings alone. Additional weight saving could be achieved by the inclusion of batteries into the load carrying structure.

Besides these technical advantages, the price of lithium-ion batteries has been falling sharply in the last two decades, while the volumetric energy density is continuously increasing (Nykvist \& Nilsson, 2015). Hence in sum, the trends of better technical usability and cheaper prices support the adaption of lithium-ion battery packs in aviation propulsion systems. 


\section{Electric motors}

Not only batteries but also the torque and power density of modern electric motors have increased over the last decades due to several technological advancements. Weight optimization was achieved using modern computational tools to optimize the mechanical structure of the rotor and the stator.

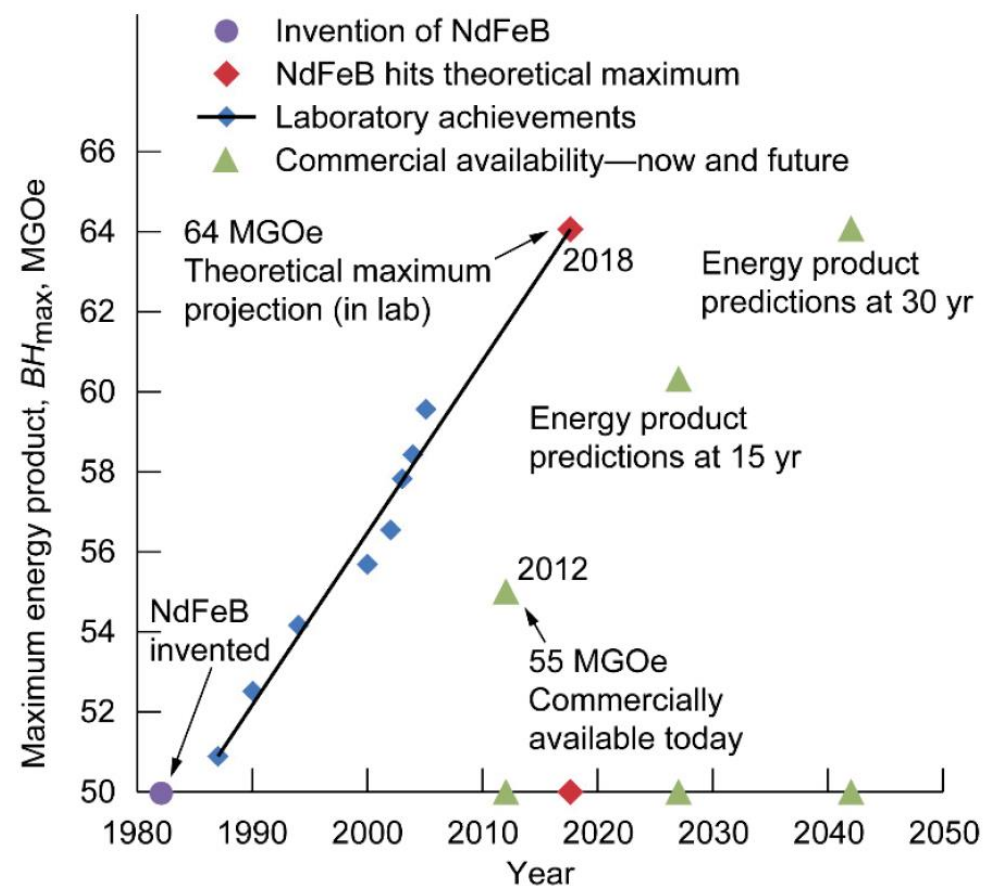

Figure 2. History and predictions of energy product improvements for neodymium iron boride $(\mathrm{NdFeB})$ sintered permanent magnets. Achievements in the laboratory (blue dots) and entry dates into market show a prediction for product improvements until 2040. Reprinted from "Assessment of technologies for noncryogenic hybrid electric propulsion," by T. P. Dever, B. B. Choi, A. M. Lowe, A. J. Provenza, K.P. Duffy, P. L. Loyselle, and C. R. Morrison, 2015, NASA/TP-2015-216588.

Modern materials such as aluminum alloys and carbon-fiber reinforced rotors help to further decrease weight, while secondary parts (mostly power electronics) decreased in weight and size.

Neodymium iron boride $(\mathrm{NdFeB})$ magnets are considered a technological breakthrough for compact electric motors. They provide powerful magnetic fields 
at very compact size. Permanent magnets can be classified by their energy product $(\mathrm{BH})_{\max }$, "the maximum product of the magnet's remanence $\mathrm{B}_{\mathrm{r}}$ and its coercivity $\mathrm{H}_{\mathrm{c}}$. Essentially, $(\mathrm{BH})_{\max }$ determines a magnet's strength: the higher the number, the stronger the magnet" (Dever et al., 2015, p. 11). Figure 2 shows the technological advancement of $\mathrm{NdFeB}$ sintered permanent magnets in the laboratory and projections to reach their theoretical maximum energy product $(\mathrm{BH})_{\max }$ in 2018. The timeframe from the laboratory to market is projected to last up to 20 years with the highest technological development reaching market around 2040.

$\mathrm{NdFeB}$ permanent magnets replace samarium cobalt $(\mathrm{SmCo})$ and alnico in most applications and provide a reduction in volume by 50\% and $90 \%$ respectively (Thompson, 2009). This new generation of rare earth magnets was introduced in 1983, but it took until the last decade for NdFeB magnets to become readily available for a full field of applications and especially in electric motors.

\section{Aerodynamic optimization}

As mentioned above, the hybrid electric design space increases the number of parameters that can be manipulated during the aircraft design process. As will be exemplarily shown, the right choice and placement of propulsors can significantly support the aerodynamic optimization process. The same applies to aeroelastic and structural design optimization, which are partially interdependent, but beyond the scope of this paper.

The aerodynamic efficiency of the fuselage and the wing can both be increased by the optimization of laminar flow. Laminar flow across the wing can be increased by a reduction in cruise speed, which allows for the use of laminar airfoils. The placement of the engines in the vicinity of the wings induces turbulent flow and pressure changes, which either directly reduce the laminar flow areas by provoking transition to turbulent flow or increase the induced drag by disturbing the elliptic lift distribution of the finite wing.

These factors all favor placement of the propulsive unit in the back of the aircraft, preferably at the tail-section. In the case of a propeller aircraft, this can also lead to increased propeller-efficiency. As shown in Figure 3, the compact size of an electric motor decreases the blocked area behind the propeller (Geiß \& Voit-Nitschmann, 2017). 


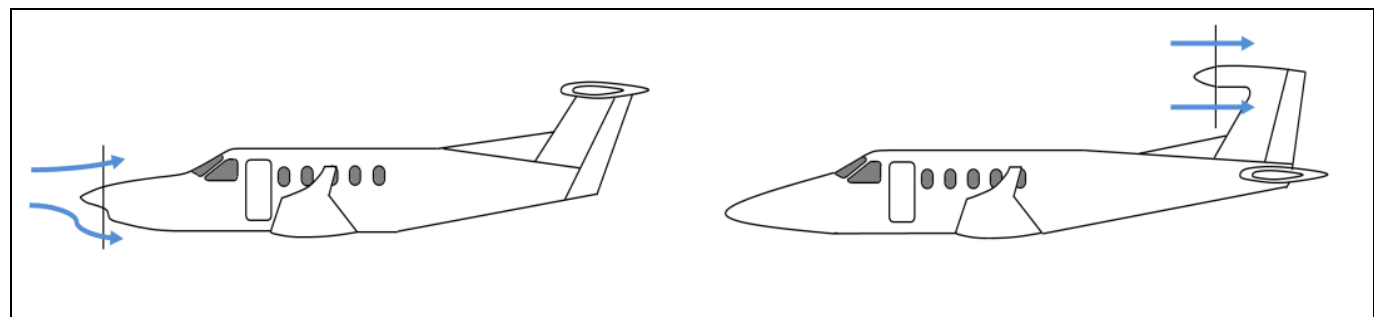

Figure 3. Comparison of a commuter aircraft airframe optimized for a turboprop engine (left) and an airframe optimized for an electric motor (right). The propeller blocking area and wetted fuselage area behind the propeller significantly reduced with the tail installed electric engine/propeller assembly, increasing the installed and propeller efficiency and reducing turbulent flow on the fuselage. Reprinted with Permission from University of Stuttgart, as described in "Sizing of fuelbased energy systems for electric aircraft," by I. Geiß and R. Voit-Nitschmann, 2017, Proceedings of the Institution of Mechanical Engineers.

Another example for new synergistic design options is the distribution of the thrust too many small propulsive units. Ducted fans can be placed around the fuselage and close to the trailing edge of the wing to ingest the boundary layer. The concept of boundary layer ingestion (BLI) is not new but did not prove practicable so far. Liu, Valencia, and Teng (2016) conclude that "with wake ingestion, the power expended can be less than the product of the forward speed and craft drag. The benefit of boundary layer ingestion (BLI) comes from reenergizing the aircraft wake, which enables less kinetic energy to be wasted" ( $p$. 1146). With the advent of distributed electric propulsion (DEP), this synergistic effect becomes more straightforward to use in aircraft design. In short, the hybrid electric design could effectively balance weight increase due to batteries and subsystems with improvements in the aerodynamic layout of an aircraft for an overall increase in efficiency and without jeopardizing flight safety.

\section{Hybrid Commuter Aircraft Concepts}

Hybrid Propulsion Architecture Components. Compared to conventionally powered aircraft, hybrid electric aircraft have additional system components which add to takeoff mass and acquisition cost. Depending on the hybrid architecture, the degree of hybridization, and operational demands, the components on the electric system can vary slightly. Typically, the following components are the main parts of a hybrid system: electric motors, gearboxes, generators, power electronics and inverters, cables, and batteries (see Figure 4).

For short range applications, the degree of hybridization is typically low, and the amount of batteries is reduced to a useful minimum. For a short distance 
hybrid aircraft, the endurance from battery capacity alone is not essential, the battery power is only used to provide additional power during peak demands, such as takeoffs and missed-approaches.

The battery can be recharged during times of low power use like in economic cruise over extended periods of time or especially during descent, where very little propulsive power is required. During these times, the excess electric power from the generators can be stored in the batteries. For mild hybrid commuter concepts, like in the automotive equivalent, no additional charging of the batteries on the ground is foreseen.
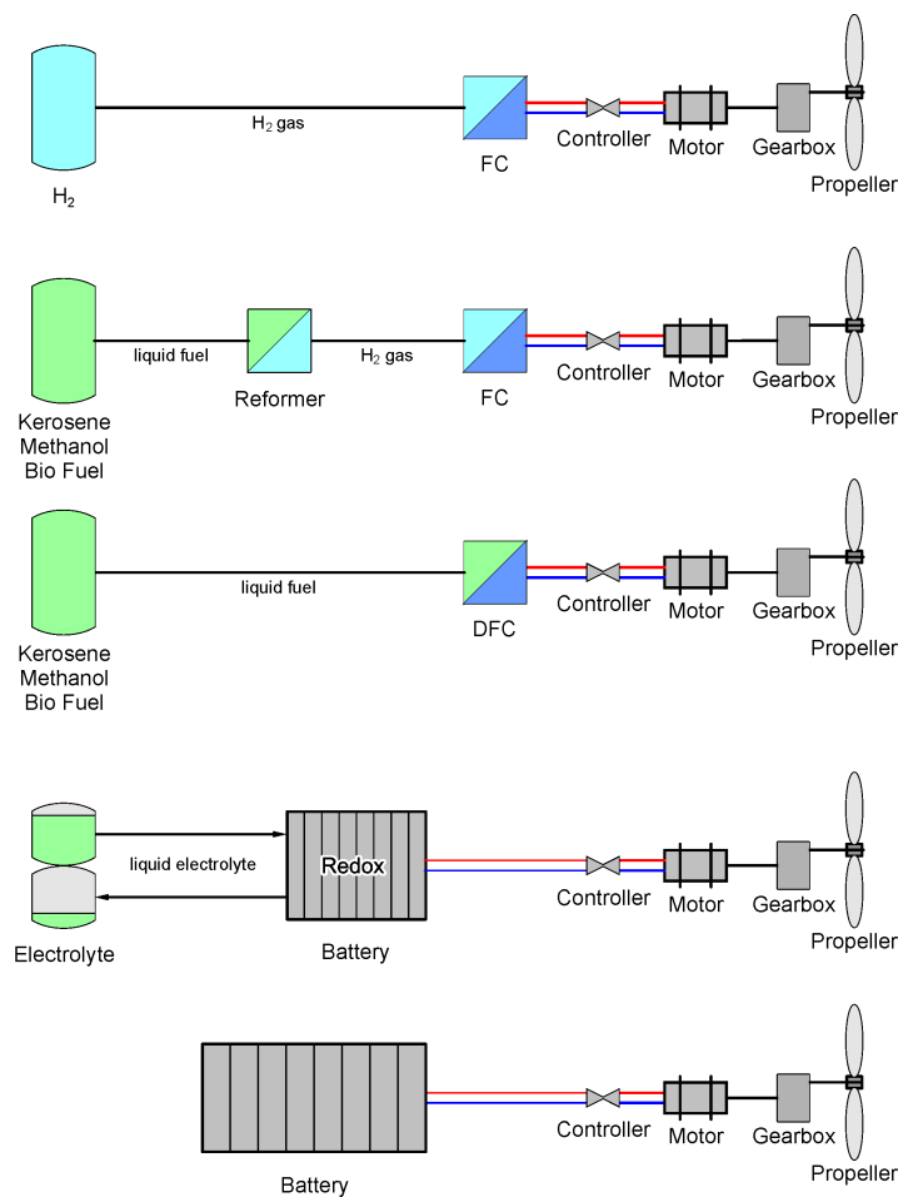

Figure 4. Hybridization scenarios and system components. Depending on the source of energy and hybridization concept (parallel or serial) some subcomponents can differ. However, the core components stay the same, only with variations in the arrangement. Reprinted from "Electric Flight - Potential and Limitations," by M. Hepperle, 2012, AVT-209 Workshop on Energy Efficient Technologies and Concepts Operation, Lisbon. Reprinted with permission. 


\section{Market Potential}

The above mentioned additional components increase acquisition cost for hybrid electric aircraft relative to their conventional counterparts. There are no exact industry numbers available yet; Siemens (2016) expects aircraft acquisition cost is increasing by $10-30 \%$, while NASA (2017) forecasts fuel savings of $26 \%$ to $56 \%$ for hybrid electric aircraft compared to conventional aircraft of similar size.

The European aircraft manufacturer Airbus (2017) indicates that the first viable product with a hybrid propulsion system will probably have 50 to 70 seats. Looking at data from the North American short-range airline sector, it seems obvious, that aircraft competitiveness usually increases with increasing seat count, while the maximum seating capacity for short routes (below $500 \mathrm{~nm}$ ) usually is at 100 seats (ESG Aviation Services, 2017).

Overall it is hypothesized, that hybrid electric commuter aircraft with 50 seats can be competitive on short-range scheduled flights, on a cost per available seat mile (CASM) basis and in direct comparison with 100 seat aircraft with conventional propulsion systems. Hence, the null hypothesis, which will be tested, states that the 50 seat hybrid aircraft is not competitive against the established 100 seat aircraft on a CASM basis.

\section{Methodology}

\section{Sources of Data}

To support or reject this hypothesis, the chosen methodology will examine the question, whether and how the cost per available seat mile of a conventionally powered 50-seat aircraft differ significantly from a conventionally powered 100seat aircraft and a hypothetical hybrid-electric 50-seat aircraft. This methodology has been chosen because hybrid electric aircraft will probably first enter the market as a short-range aircraft with 50 seats or less, whereas the most competitive short-range aircraft typically have 100 seats.

The amount of available operational data related to European airlines is limited. Even for North American airlines, the amount of data is not abundant, but there are several sources that provide sufficient information to compare aircraft models in service on direct operating costs. The data used in this research paper was gathered from the database of The Airline Monitor (ESG Aviation Services, 2017). 
The Airline Monitor lists only a handful of carriers supporting short routes below 500 nautical miles with their aircraft, but several use a fleet of Embraer Regional Jets with different seating limitations that lend themselves to compare short-range aircraft in the same operational airline environments. Therefore, the Embraer EMB 145 50-seat aircraft and the EMB 190 with 100 seats were chosen for this comparison (ESG Aviation Services, 2017).

\section{Data Reliability, Validity, and Comparability}

The data was considered reliable, due to it being provided by The Airline Monitor, a long time and independent industry analyst; data provided by this source are used by government agencies like the US Department of Transportation (ESG Aviation Services, 2017). Data validity is assumed for the direct comparison of the two Embraer (EMB) Jet aircraft and a hypothetical hybrid version thereof for planned flight distances of up to 500 nautical miles. Validity and in particular the ability to transfer findings to other non-jet aircraft are limited by the small number of datasets for short range aircraft.

\section{Data Treatment and Statistical Analysis}

Operational data of the EMB145 (50-seater) and EMB190 (100-seater) aircraft was collected from The Airline Monitor for the years 2010 to 2016. The aircraft cost per available seat mile (CASM) was chosen as a key performance indicator since it is a common parameter for comparison and includes important operational costs like flight crew expenses, fuel, and maintenance.

The data was gathered in a spreadsheet (see Table 1) to compare a 50-seat short-range jet in conventional and hybridized configuration to a conventionally powered 100 seat version.

The CASM data for the hybridized 50-seater were calculated with the conservative assumption of a $25 \%$ reduction in fuel usage and cost. Hence a quarter of the fuel cost per CASM was subtracted from the cost per available seat mile values of the conventional EMB 145 to generate the CASM data of the hypothetical hybrid Embraer 145 (EMB 145-hybrid).

Two $t$-tests were conducted to compare the operational costs of the fleets. The two-sample $t$-tests were performed using Microsoft Excel; variance levels were recalculated and confirmed by hand since they appeared to be slightly larger than anticipated. The first two-tailed $t$-test was used to verify, whether the mean CASM of the conventional EMB 145 is significantly higher than the mean CASM of the EMB 190. 
Table 1

Cost per available seat mile (CASM) of the two common regional jets Embraer 145, 190, and a hypothetical hybrid version of the EMB 145. Units are US cents.

\begin{tabular}{|c|c|c|c|c|}
\hline \multirow[b]{2}{*}{ Year } & \multicolumn{3}{|c|}{ EMB 145} & \multirow{2}{*}{$\begin{array}{l}\text { EMB } 190 \\
\text { CASM }\end{array}$} \\
\hline & CASM & fuel cost & CASM hybrid & \\
\hline \multirow[t]{3}{*}{2010} & 10.12 & 5.22 & 8.82 & 8.34 \\
\hline & 11.61 & 5.61 & 10.21 & 10.81 \\
\hline & 9.37 & 5.02 & 8.12 & 8.79 \\
\hline \multirow[t]{3}{*}{2011} & 11.86 & 7.43 & 10.00 & 10.32 \\
\hline & 12.61 & 6.77 & 10.92 & 10.74 \\
\hline & 11.48 & 7.76 & 9.54 & 12.89 \\
\hline \multirow[t]{3}{*}{2012} & 11.66 & 7.10 & 9.89 & 10.98 \\
\hline & 12.14 & 6.99 & 10.39 & 11.15 \\
\hline & 11.43 & 7.15 & 9.64 & 13.67 \\
\hline \multirow[t]{4}{*}{2013} & 12.37 & 7.45 & 10.51 & 11.87 \\
\hline & 12.99 & 7.39 & 11.14 & 12.28 \\
\hline & 12.07 & 7.47 & 10.20 & 12.07 \\
\hline & & & & 8.66 \\
\hline \multirow[t]{4}{*}{2014} & 12.28 & 7.11 & 10.50 & 11.88 \\
\hline & 13.19 & 7.18 & 11.40 & 14.42 \\
\hline & 11.86 & 7.08 & 10.09 & 11.43 \\
\hline & & & & 8.52 \\
\hline \multirow[t]{3}{*}{2015} & 10.45 & 4.89 & 9.23 & 9.65 \\
\hline & 11.70 & 5.06 & 10.44 & 8.01 \\
\hline & 9.02 & 4.63 & 7.86 & 9.99 \\
\hline \multirow[t]{2}{*}{2016} & 11.18 & 3.56 & 10.29 & 8.87 \\
\hline & 9.64 & 3.50 & 8.77 & 9.32 \\
\hline
\end{tabular}

Even though the absolute price difference is only a few cents, a systematic difference seems visible. Therefore a cut-off confidence level of $95 \%$ is chosen for both tests. The second two-tailed test is used to examine if the hybridization of the 50-seater leads to a significantly lower CASM relative to the conventional 100 -seater. 


\section{Results}

The results indicate that generally speaking, the standard 50-seater is more expensive on short routes than its 100-seat competitor. The hybridization and an associated reduction in fuel burn in the order of $25 \%$ can give the 50 -seater a competitive advantage, even against the established 100-seater.

Table 2

T-test to determine a statistically significant cost advantage of the EMB 190 compared to the EMB 145. Data from the operational years 2010 to 2016

\begin{tabular}{|c|c|c|c|c|c|c|c|}
\hline & \multicolumn{3}{|c|}{$E M B 145$} & \multicolumn{3}{|c|}{ EMB 190} & \multirow[b]{2}{*}{$t$} \\
\hline & $\mathrm{n}$ & $M$ & SD & $\mathrm{n}$ & $M$ & SD & \\
\hline CASM & 20 & 11.45 & 1.17 & 22 & 10.67 & 1.80 & 1.639 \\
\hline
\end{tabular}

For the operational years between 2010 and 2016, the mean CASM for the conventional 50 -seater was at 11.45 cents $(\mathrm{SD}=1.17)$ significantly higher than the mean CASM for the 100-seater at 10.67 cents $(\mathrm{SD}=1.80), \mathrm{t}(36)=1.693, \mathrm{p}=$ 0.0495 (see Table 2). While for the hybrid version, the $t$ test showed the CASM $(\mathrm{M}=9.90, \mathrm{SD}=0.94)$ to be significantly lower than the EBM $190 \mathrm{CASM}(\mathrm{M}=$ $10.67, \mathrm{SD}=1.80), \mathrm{t}(32)=-1.760, \mathrm{p}=0.0440($ see Table 3$)$.

Consequently, the null hypothesis has to be rejected and the research hypothesis can be supported.

Table 3

T-test to determine a statistically significant cost advantage of the hybridized EMB 145 compared to the conventional EMB 190 during the operational years 2010 to 2016

\begin{tabular}{|c|c|c|c|c|c|c|c|}
\hline & \multicolumn{3}{|c|}{ EMB 145 hybrid } & \multicolumn{3}{|c|}{$E M B 190$} & \multirow[b]{2}{*}{$\mathrm{t}$} \\
\hline & $\mathrm{n}$ & $\mathrm{M}$ & SD & $n$ & $M$ & SD & \\
\hline CASM & 20 & 9.90 & 0.94 & 22 & 10.67 & 1.80 & -1.760 \\
\hline
\end{tabular}

Looking at Figure 5, it can be seen that meager fuel prices like in 2015 and 2016 can reduce the cost advantage of a hybrid 50 seat EMB 145 compared to the 100-seater, while still offering greater flexibility of the smaller aircraft at the same price point. By contrast, operational years with higher fuel cost, like 2012, show the future potential of hybridization efforts, where the cost savings become substantial compared to the legacy propulsion technology as fuel prices rise further. 


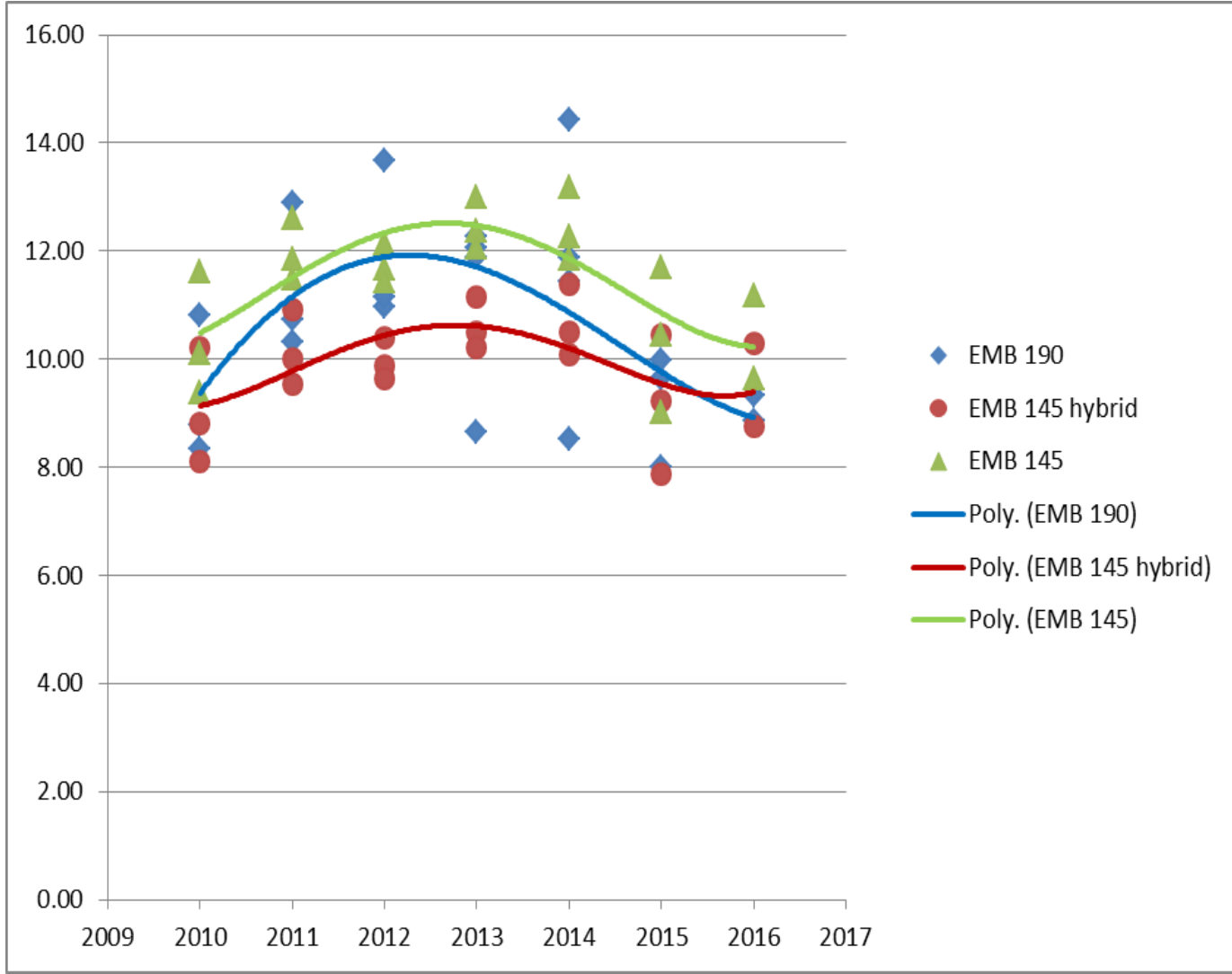

Figure 5. Graphical comparison of cost per available seat mile data of the EMB 145, EMB 145 hybrid, and the EMB 190 between operational years of 2010 and 2016

It should be noted that this comparison is based on one, carefully chosen aircraft family. Therefore, the result should not be generalized without an operational context of where and how the aircraft are used in mind. Nevertheless, the Embraer Regional Jets represent a good benchmark for the short-range market with an aircraft market share of $40 \%$ in North America (AirInsight, 2011). Furthermore, they represent current market trends, which shift towards jets with around 100 seats. Regional airline analysts from AirInsight observe that "today the 50-seaters have grown unpopular because of higher fuel costs. The regional jet segment is better defined at between 75 and 100 seats" (AirInsight, 2011). Hence, future work should investigate a broader spectrum of short-haul aircraft.

Overall, the results of this study indicate that the hybridization of small regional jets can make aircraft with only 50 seats more competitive than the established 100 seat aircraft because hybrid electric aircraft eliminate the costrationale for choosing bigger aircraft. 


\section{Conclusion}

To the authors' knowledge, the economic competitiveness of hybrid electric aircraft, especially for small regional aircraft and short-range scheduled flights, has not yet been studied.

Since variable costs heavily depend on operational efficiencies, the total cost of ownership is not a simple metric for cost comparison. The fuel savings on a cost per available seat mile basis lends itself as a good tool to investigate competitiveness on increased efficiencies through hybrid technologies.

It was shown that a hybrid 50 seat regional jet could be competitive against a conventional 100 seat aircraft on short routes of $500 \mathrm{NM}$. This finding indicated that entry into the market could be made with hybrid electric aircraft seating only 50 passengers, therefore increasing the chance to bring hybrid aircraft to market within the next 10 to 15 years on existing technology levels.

Most notably, this is the first study, which has investigated the cost sensitivity for hybrid electric aircraft on an operating cost basis. The results provided a compelling case for companies and start-ups to consider investing in hybrid aircraft technologies. 


\section{References}

Airbus Group. (2017). E-Aircraft Roadmap. Retrieved from http://company.airbus.com/responsibility/airbus-e-fan-the-future-ofelectric-aircraft/e-aircraft-roadmap.html

AirInsight. (2011). The Dynamic Regional Jet Market - Commercial Aviation Analysis. Retrieved from: https://www.airinsight.com/the-dynamicregional-jet-market/

Crabtree, G., Kocs, E., and Trahey, L. (2015). The energy-storage frontier: Lithium-ion batteries and beyond, MRS Bulletin, 40, 1067-1076. doi: $10.1557 / \mathrm{mrs} .2015 .259$

Deng, Y., Yang, C., Zou, K., Qin, X., Zhao, Z., \& Chen, G. (2017). Recent advances of Mn-Rich LiFe1-yMnyPO4 $(0.5 \leq \mathrm{y}<1.0)$ cathode materials for high energy density lithium ion batteries. Advanced Energy Materials, 7(13), n/a. doi:10.1002/aenm.201601958

Dever, T. P., Choi, B. B., Lowe, A. M., Provenza, A. J., Duffy, K. P., Loyselle, P. L., \& Morrison, C. R. (2015). Assessment of technologies for noncryogenic hybrid electric propulsion. NASA/TP-2015-216588.

ESG Aviation Services. (2017). The Airline Monitor, 24-30. Retrieved from www.airlinemonitor.com

European Union. (2011). Flightpath 2050: Europe's vision for aviation: maintaining global leadership and serving society's needs. Luxembourg: Publications Office of the European Union.

Geiß, I., \& Voit-Nitschmann, R. (2017). Sizing of fuel-based energy systems for electric aircraft. Proceedings of the Institution of Mechanical Engineers, Part G: Journal of Aerospace Engineering, 231(12), 2295-2304. doi:10.1177/0954410017721254

Hepperle, M. (2012). Electric Flight - Potential and Limitations. AVT-209 Workshop on Energy Efficient Technologies and Concepts Operation, Lisbon. Retrieved from https://www.mh-aerotools.de// 
Liu, C., Valencia, E., \& Teng, J. (2016). Design point analysis of the turbofandriven turboelectric distributed propulsion system with boundary layer ingestion. Proceedings of the Institution of Mechanical Engineers, Part G: Journal of Aerospace Engineering, 230(6), 1139-1149. doi:10.1177/0954410015605546

NASA. (2017). Overview of NASA Electrified Aircraft Propulsion Research for Large Subsonic Transports. Retrieved from https://ntrs.nasa.gov/archive/nasa/casi.ntrs.nasa.gov/20170006235.pdf

Nykvist, B., \& Nilsson, M. (2015). Rapidly falling costs of battery packs for electric vehicles. Nature Climate Change, 5(4), 329. doi:10.1038/nclimate2564

Pornet, C., \& Isikveren, A. T. (2015). Conceptual design of hybrid-electric transport aircraft. Progress in Aerospace Sciences, 79, 114. doi:10.1016/j.paerosci.2015.09.002

Rohan, J. F., Hasan, M., Patil, S., Casey, P., and Clancy, T. (2014). Energy Storage: Battery Materials and Architectures at the Nanoscale, ICT Energy - Concepts Towards Zero - Power Information and Communication Technology, Dr. Giorgos Fagas (Ed.), InTech, doi: $10.5772 / 57139$

Siemens AG. (2016, July 4). Electric Flight Takes Off. Retrieved from

Stricker, J. M. (2003). Aero propulsion laboratory, briefing to committee members S. Michael Hudson and Willard J. Dodds. Aeronautical Journal of the Royal Aeronautical Society, 72, 209-229.

Sustainable Aviation. (2008). Sustainable aviation co2 roadmap. Retrieved from http://www.sustainableaviation.co.uk/road-maps/

Thompson, M. T. (2009). Practical issues in the use of NdFeB permanent magnets in maglev, motors, bearings, and eddy current brakes. Proceedings of the IEEE, 97(11), 1758-1767. doi:10.1109/JPROC.2009.2030231 